\title{
A GIS-BASED APPROACH TO RISK MAPPING OF LASSA FEVER OUTBREAK IN AKURE SOUTH LOCAL GOVERNMENT AREA, NIGERIA
}

\author{
IFEJUBE, Oluwafemi John ${ }^{1}$, BABALOLA, Sunday Oyetayo*2, MUKAILA, Ibrahim Olanrewaju ${ }^{3}$ and BADEWA, Adesola \\ Oluwatoyin $^{4}$ \\ 1Geo-Information Science and Earth Observation (ITC), University of Twente, Enschede, Netherlands \\ ${ }_{2}$ Department of Surveying and Geoinformatics, Federal University Oye Ekiti, Ekiti State, Nigeria. \\ 3\&4Department of Surveying and Geoinformatics, Federal University of Technology Akure, Nigeria. \\ Corresponding Author*: sunday.babalola@fuoye.edu.ng
}

Commission 4, WG 7

KEY WORDS: Lassa fever, Infectious Disease, Public Health, Epidemiology

\begin{abstract}
Lassa fever is an acute viral illness, which is endemic in some counties in West Africa, including Guinea, Liberia, Sierra Leone and parts of Nigeria. It is caused by the Lassa virus, which is primarily hosted by multi-mammate rats that live in and around houses. This study sees the need to enhance public awareness by producing risk maps of Lassa fever for the study area. In a bid to understandand predict the prevalence of the disease in Akure South Local Government Area. Temporal and spatial analyses of Lassa fever caseswere carried out, information about related environmental variables such as temperature, rainfall, vegetation, and elevation were obtained. These data sets from primary and secondary sources were integrated independently as predictor variables for the developed risk model. The accessibility of incidences of Lassa fever to health centres was determined and analysed. The risk map produced indicates that areas about the Ijoka community are at higher risk of being affected by a future Lassa fever outbreak than other areas. The model developed an understanding of the high risk and potential outbreak of Lassa fever to alert the general public of the virus tocurb the future outbreak. However, future research can be on the control and prevention of Lassa fever in the study area.
\end{abstract}

\section{INTRODUCTION}

\subsection{Background to the Study}

The World Health Organization (WHO) defined health as a state of complete physical, mental, and social well-being, and not merely the absence of disease or infirmity. Lassa Fever (LF) is an infection caused by the Lassa virus, a single-stranded RNA virus (Eze et al., 2010). Lassa fever is a type of viral haemorrhagic fever with high mortality rates in hospitalised patients. A rat common in endemic areas, known as mastomys natalensis is the natural host of the disease (Richmond J.K. \& Baglole D.J., 2003). Lassa fever was first quarantined in 1969 when two missionary nurses became sick and died in Lassa, Nigeria. Clinical signs range from minor febrile sickness to severe vascular leakage, haemorrhage, shock, and death. Starting of Lassa fever into humans occurs through a planned orunplanned connection with the excreta of the natural reservoir, the rodent Mastomys natalensis, although precise modes of transmission are not well characterised (Monath TP et al., 1974). Human-to-human transmission of Lassa virus (LASV) through contact with blood and other bodily fluids has been documented, particularly in clinical settings (Fisher-Hoch S.P. et al., 1995). The disease occurs in all age groups and both sexes. For this reason, the World Health Organization recorded LF among main concern diseases requiring urgent research and development attention (Gibb, Moses, Redding, \& Jones, 2017). The most recent outbreak of Lassa fever started on 16 December 2016 in Ogun State, Nigeria. The disease eventually increased in number and spread to 14 other states in Nigeria,and to three neighbouring countries of Benin, Togo and BurkinaFaso (WHO, 2017).

According to the World Health Organization (2017), a risk map is a map of a community or geographical zone that classifies the places and structures that might be harmfully affected in the occurrence of a hazard.. Since the late 17th century, mapping has been a critical tool used by physicians and public health officials confronting local outbreaks, regional epidemics, and broad pandemic events (Koch T., 2012). Risk maps help trace the significant hazards; they can create common standards for decision-making, offer a record of historical events that have had an adverse influence on the community, and identify risksso a community may find solutions and take precautions. Mapping was a critical medium in which data on "what ishappening" could be collected, organised, analysed, and presented. Because local and foreign workers often spoke different languages, maps served as a lingua franca promoting shared knowledge among those who otherwise had difficulty communicating.

GIS has been used in the investigation and observing of vectorborne as well as water-borne diseases, and the ones concerning the environmental health, disease policies and planning, the existing health situation in the area, the generationand analysis of research hypotheses, identification of high-risk health groups, planning and programming of activities, and monitoring and evaluation of interventions (Jerrett et al., 2003; Ibidolapo \& SAM 2018; Hay, Randloph, \& Rogers, 2002; Kaushal, A. \& Johnson, 2003). GIS has enabled researchers to determine locations of high prevalence areas and populations at risk (Gupta, Jay, \& Jain 2003; Prashanthi Devi, Manickiam, Balasubramanian, 2003 \& Saka, 2017).

Hanafi-Bojd et al., (2012), combined environmental factors by weighted multi criteria evaluation for mapping malaria hazard area and developed malaria risk map by overlaying weighted hazard, land use/land cover, population density, malaria incidence, development factors and intervention methods. Abasola O. Olugasa, (2015) used geographical information system to produce thematic maps of Lassa fever in Liberiageographic co-ordinates of locations of LF cases were summated into thematic maps, and sub-classified into age, LASV-activity and seasonal pattern. Seasonal index wascomputed based on frequency of cases during the months of the 
year, categorized into rainy and dry seasons. Fichet-Calvet \& Rogers, (2009) in his research, presented three differentanalyses (models), one superimposing Lassa fever outbreaks on the mean rainfall surface (Model 1) and the other two using non-linear discriminant analytical techniques.

The anticipated success-level of clinical efforts towards combating the outbreak of LF in Nigeria has been impeded due to the lack of appropriate risk maps to guide the deployment of relevant medical personnel. Lassa fever is a public health threat because it is endemic in the country, and Ondo state has the second-highest number of cases of this disease. Akure South Local Government has been reported to be one of the highest local governments in Ondo state endemic with Lassa fever. The risk awareness of Lassa fever through public information and communication has not been effective enough because of the unavailability of risk maps. Although the government has tried making public awareness through radio jingles, posters and TV ads, the public's response has not been good enough. Therefore, there is a need to invoke a sense of urgency, fear, and anxiety in the minds alongside the causes, symptoms, treatment, and Lassa fever prevention. The populace needs to visualise the spread and potential places that may be affected if nothing is done about it. Several researchers have picked interest in this concept, as the epidemic disease has been subjected to public attraction over the years. Nonetheless, few of them have considered it from the geospatial viewpoint, and most of the maps produced were small-scale maps. Like many other states in this country, Ondo state has a map that shows the affected local governments. This is too generalised to understand the location, pattern, trend, and probability of the disease within the area. Therefore, there is a need to investigate and map the risk of LF outbreak in Ondo State and analyse the accessibility of infected patients to treatment facilities to create an awareness to people of this deadly disease This study is unique because not only did it cover a much more relatively more minor area, but it also employed a much more updated database and took accessibility to treatment facilities among others into consideration, as these are factors increasing the risk in this part of the world.

\subsection{Study Area}

Ondo State is one of the 36 states in the Federal Republic of Nigeria situated between longitudes $4^{\circ} 15^{\prime} \mathrm{E}$ and $6^{\circ} 00^{\prime} \mathrm{E}$ of the Greenwich meridian and latitude $5^{\circ} 45^{\prime} \mathrm{N}$ and $7^{\circ} 45^{\prime} \mathrm{N}$ of the North of the equator, in the Southwestern geopolitical zone of the country. The study area, Akure South Local Government Area (LGA) is one of the six (6) Local Government areas classified as the Ondo central senatorial district. One of the eighteen (18) LGAs in Ondo State with its headquarter in Akure, which equally doubles as the state capital and the most populated local government area in the State. It is located between latitude $7^{\circ}$ $21^{\prime} \mathrm{N}$ and $7^{\circ} 50^{\prime} \mathrm{N}$ and Longitude $5^{\circ} 50^{\prime}$ and $7^{\circ} 25^{\prime}$. It is about 250 meters above sea level, with a landmass covering an area of 331 square kilometres and an average elevation of $353 \mathrm{~m}$. Akure South LGA's climate is tropical with different seasons: the rainy season (April - October) and dry season (November - March). The temperature over time goes from $21^{\circ} \mathrm{C}$ to $29^{\circ} \mathrm{C}$ and high relative humidity of about $80 \%$ (Omosehinmi \& Arogunjo, 2016). The yearly precipitation fluctuates from $1150 \mathrm{~mm}$ in the northern parts to $2000 \mathrm{~mm}$ in the southern region (Afolabi, Akinneye, \& Igiekhume, 2019). It is bounded on the northeast by Akure North Local Government Area and on the northwest by Ifedore Local Government Area, Idanre Local Government Area bonded on the southern part (seefigure below).

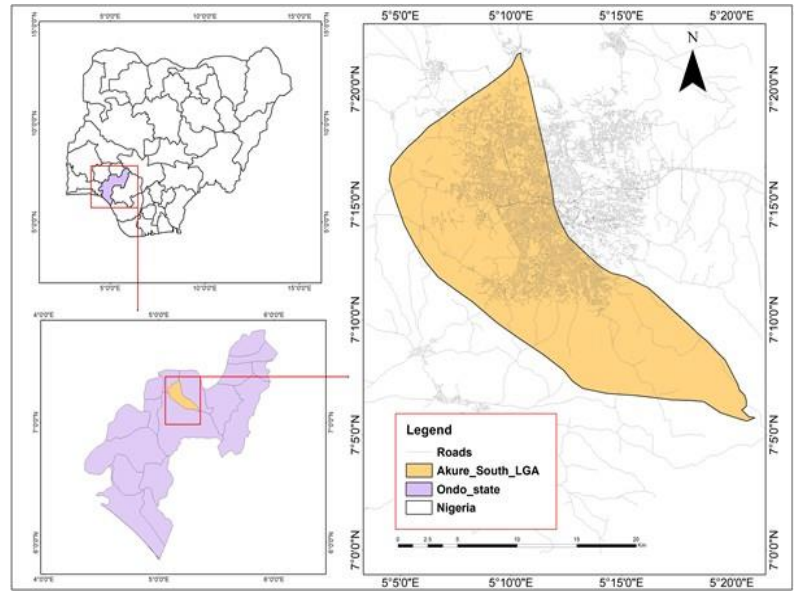

Figure 1. Map of Nigeria showing the study area

\section{METHODS AND MATERIALS USED}

Through an extensive literature review, some factors have been identified to influence the possibility of the disease's occurrence. These factors are highlighted below:

- Rats stay in vegetation in the rainy season and at this moment infect one another during mating. They also infect hunters and villagers who consume rats directly in rural areas

- Cases are more frequent in dry seasons; therefore, lower rainfall increases the risk of Lassa fever occurrence

- High temperatures increase Lassa fever decay

- Rats stay around dump sites and dirty areas in search of food in built-up areas

- High elevations are high-risk areas

- Lassa fever can be easily transmitted to people living around

With respect to these factors, several sets of data were sought. These datasets were obtained, prepared and integrated into a geodatabase, and finally a spatially explicit model was used to combine the datasets resulting in an estimation of risk across the area. the desired risk map. This is graphically summarized in Figure 2.

Coordinates of the health centres were also obtained to analyse the accessibility of people residing in affected areas to treatment facilities. The datasets obtained are highlighted in the tables below:

\begin{tabular}{|r|r|r|r|c|}
\hline $\boldsymbol{S} /$ Data & Source & $\begin{array}{r}\text { Equipment } \\
\text { used }\end{array}$ & Year \\
$\boldsymbol{N}$ & & Field & Garmin GPS & 2019 \\
\hline 1. & $\begin{array}{c}\text { Coordinates of the cases } \\
\text { of Lassa fever }\end{array}$ & survey & & \\
\hline 2. & $\begin{array}{r}\text { Coordinate of places with } \\
\text { poor waste management }\end{array}$ & $\begin{array}{r}\text { Field } \\
\text { survey }\end{array}$ & Garmin GPS & 2019 \\
\hline
\end{tabular}

Table 1. List of primary data

\begin{tabular}{|l|l|l|l|l|}
\hline$S$ & Data & Source & $\begin{array}{l}\text { Resolu } \\
\text { tion }\end{array}$ & Year \\
$N$ & & & \\
\hline 1 & $\begin{array}{l}\text { List of cases } \\
\text { of Lassa fever } \\
\text { in the study } \\
\text { area }\end{array}$ & $\begin{array}{l}\text { Ondo State Ministry of } \\
\text { Health Alagbaka, Akure, }\end{array}$ & - & 2016 \\
& & - & 2018 \\
\hline
\end{tabular}




\begin{tabular}{|c|c|c|c|c|}
\hline 2 & $\begin{array}{l}\text { Google Earth } \\
\text { Imagery }\end{array}$ & Digital Globe & $60 \mathrm{~cm}$ & 2018 \\
\hline 3 & $\begin{array}{l}\text { Base map of } \\
\text { study area }\end{array}$ & www.openstreetmap.org & - & 2019 \\
\hline 4 & Rainfall data & $\begin{array}{l}\text { Centre for Space Research } \\
\text { and Application (CESRA) }\end{array}$ & - & $\begin{array}{l}2008 \\
-201 \\
8\end{array}$ \\
\hline 5 & $\begin{array}{ll}\text { Landsat } & 8 \\
\text { imagery } & \end{array}$ & www.earthexplorer.usgs.gov & $30 \mathrm{~m}$ & 2019 \\
\hline 6 & $\begin{array}{l}\text { Temperature } \\
\text { data }\end{array}$ & www.earthdata.nasa.gov & $1 \mathrm{~km}$ & 2019 \\
\hline 7 & Elevation data & www.earthexplorer.usgs.gov & $30 \mathrm{~m}$ & 2019 \\
\hline 9 & $\begin{array}{l}\text { Coordinate of } \\
\text { health centres }\end{array}$ & $\begin{array}{l}\text { Olugbamila's field survey }^{(1)} \\
\text { Aladetuyi's field survey }^{(2)}\end{array}$ & - & $\begin{array}{l}2018 \\
2015\end{array}$ \\
\hline
\end{tabular}

Table 2. List of secondary data

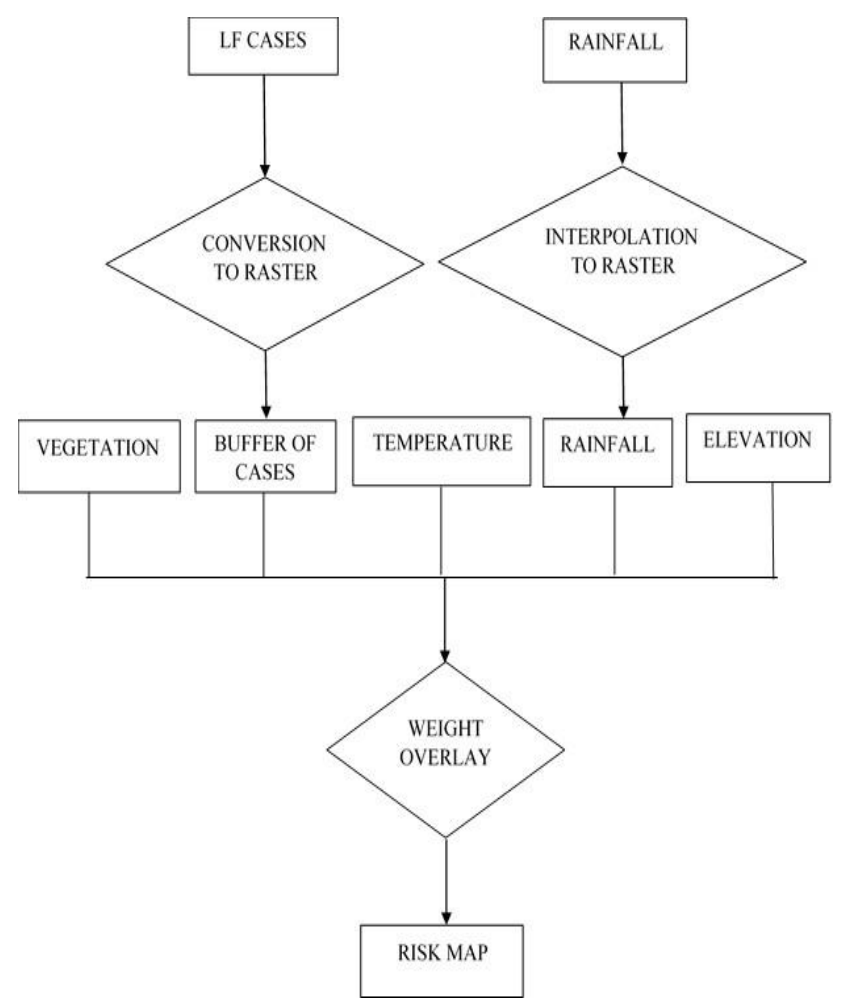

Figure 2. Chart showing the overview of project method

\subsection{Database Design}

The creation of a clean, digital database is the most important and complex task upon which the usefulness of GIS depends. The design is a framework, plan, or guide for database creation; hence, it is an essential phase of database creation (Kunfoniyi O., 1998). A spatial database is the heart of any CIS. Determining user requirements is the first step in database design. This is required to ascertain the application and identify the required attributes and various entities to make the database. The database can thus be created in line with the conceptualisedideals known as data modelling.

\subsection{Creation of the Base Map of the Study Area}

The imagery of the study area was downloaded from Google Earth. A map was then downloaded from Open Street Map (OSM) website (www.openstreetmap.org); the downloaded map was in OSM format and was converted to shapefiles. This was imported into the QGIS software and exported as point, polyline, and polygon shapefiles. After overlaying the map on the imagery, some other spatial data were added by digitizing the area's downloaded satellite imagery.

\subsection{Importing the Spatial Data}

The coordinates recorded from field surveys were recorded and stored in a spreadsheet environment using Microsoft Excel and saved as a CSV file. This file was then imported into the ArcMap environment with the correct coordinate system's data frame. The locations of each item were displayed using theNorthings and Eastings. The displayed event was then exported as a point shapefile using the coordinate system of the data layer.

\subsection{Processing of Environmental Variables}

The environmental variables are rainfall, temperature, and elevation. Rainfall data were obtained from the Centre for Space and Research and Applications (CESRA), Federal University of Technology Akure Nigeria. The average (rainfall in millimeters) was then computed for each ground station and interpolated for the study area. The type of interpolation used is the Inverse Distance Weighting (IDW) method and performed using the ArcMap software. Temperature data from NASA Terra MODIS satellite sensor data, Elevation from SRTM DEM, both the temperature and elevation data had to be clipped, using theAkure South shapefile as output extent.

\subsection{Land Use / Land Cover Classification}

Landsat 8 OLI imagery was downloaded from https://earthexplorer.usgs.gov/, using Google chrome software on a computer connected to the Internet. Necessary settingswere made to ensure that the imagery met the desiredspecification regarding the location and time, and absence of cloud cover. The downloaded zip file was then extracted using WinRAR, and the eleven (11) bands as TIFF files can now be accessed. Three bands: Band 5, Band 4 and Band 3, were combined to form a composite. This composite is a colour infrared composite, making it easier to recognize our desired classes' area in the imagery. Areas of interest (AOIs) on the composite raster, averaging and saving as a signature layer. Thisprocess is repeated for the other classes, one layer for each class. Trained classes were generated for Rocks, Vegetation, Bare Lands and Built-up areas and saved as a signature file. Supervised classification was completed in ArcGIS 10.6 using composite raster and signature file as input to produce a raster file classified for the desired classes.

\subsection{Extraction of Vegetation Data}

Normalized Difference Vegetation Index is a simple but effective means of quantifying vegetation. It normalizes green leaf scattering in the Near Infrared wavelength and chlorophyll absorption in the red wavelength. The range value of an NDVI is -1 to 1: Negative values of NDVI (values approaching -1) correspond to water. Values close to zero $(-0.1$ to 0.1$)$ correspond to barren areas of rock, sand, or snow. Low, positive values represent shrub and grassland (approximately 0.2 to 0.4 ), while high values indicate temperate and tropical rainforests(values approaching 1).

For Landsat, Band 5 and Band 4 represent near-infrared (NIR) and Red, respectively. The raster calculator on QGIS was used 
to calculate the Normalized Difference Vegetation Index (NDVI)

$$
\mathrm{NDVI}=\frac{\mathrm{NIR}-\mathrm{RED}}{\mathrm{NIR}+\mathrm{RED}}
$$

where $\quad$ NDVI $=$ Normalized Difference Vegetation Index NIR $=$ Near Infrared reflectance RED $=$ Red reflectance

\subsection{Nearest Neighborhood Analysis}

Nearest neighbor analysis (NNA) is an example of point pattern analysis, to understand the pattern of features. This analysis was used to determine if the LF cases are dispersed, clustered, or randomly distributed statistically. The spatial pattern of Lassa fever cases was analyzed using the Average Nearest Neighbor tool in ArcGIS. The confidence level used is 95\%, and the distance method used is the Euclidean distance.

\subsection{Closest Facility Analysis}

The Closest Facility analysis layer helps determine the closest facility or facilities to an incident based on a specified network cost. The closest facility solver finds the cost of travelling between incidents and facilities and determines which are nearest to one other - the output a ranking of facilities by least impedance to or from incidents and routing directions between them. The analysis helps find the closest facilities to the incidence and creates the shortest route to facilities. The closest route was grouped into three classes being $0-500 \mathrm{~m}, 500-1000 \mathrm{~m}$ and above. Closest facility analysis of Lassa fever incidences to treatment facilities, this analysis was done on the ArcGIS environ under network analyst which route is a sub under it, where the closest routes of patients to the closest healthfacilities around were found. The incidences are the Lassa fever cases, while the facilities are the nearby health centres or hospitals that patients can quickly go to for immediate checkup; this analysis also helps patients know which of the facilities is the closest to their location.

\subsection{Weighted Overlay}

The Weighted Overlay tool applies one of the most used overlay analysis approaches to solve multi-criteria problems such as site selection and suitability models. The weight overlay tool overlays several rasters using a standard measurement scale and weights each according to its importance.

The analysis was used to combine or integrate the datasets as choices for the criteria used to obtain the desired product. The type of analysis used here is Weight overlay analysis. Sets of data used are Vegetation, Rainfall. Temperature, Elevation and LF cases.

Figure 3 shows the summary of the layers used in this analysis.
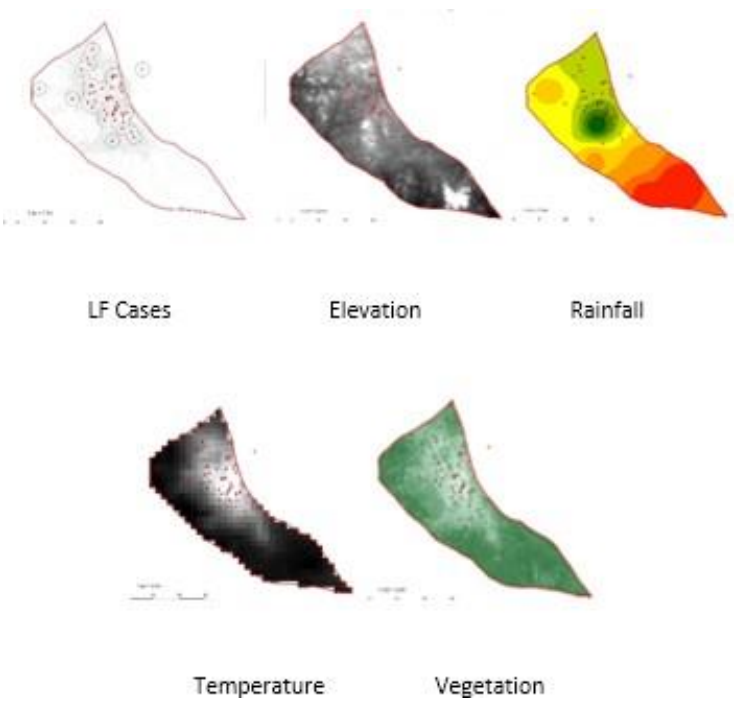

Figure 3. Raster layers used in the weight overlay analysis

\section{RESULTS AND DISCUSSIONS}

The data obtained and processed were presented in maps, charts, and graphs to make it more meaningful and easier to understand when visualized - the spatial distribution of Lassa fever cases, health centres and dumpsites. On ArcGIS, the Lassafever cases, the health centres and dumpsites, including the landfill at Igbatoro, serve as the general area where waste is being dumped when packed from other town areas picked with handheld GPS, as the point data as shown in figure 4 below.

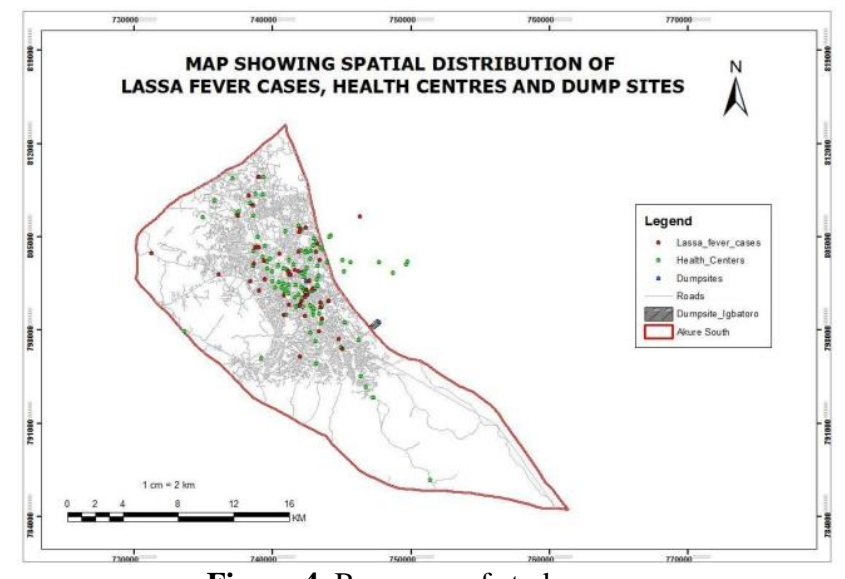

Figure 4. Base map of study area

\subsection{Weighted Overlay Analysis.}

In the risk map production for Lassa fever, each mentioned variable was assigned a different weight that sums to $100 \%$. The variables were weighted with respect to the possibility of its effect on likelihood of transmission. Directtransmission means the location of more cases is moreprominent than other factors. The continuous seasonal outbreak means rainfall and temperature contributes significantly as well. Summarily, the weights assigned are: LF cases -30\%; Rainfall-25\% Temperature- 20\% Elevation- $15 \%$ Vegetation- $10 \%$. The result is shown below: 


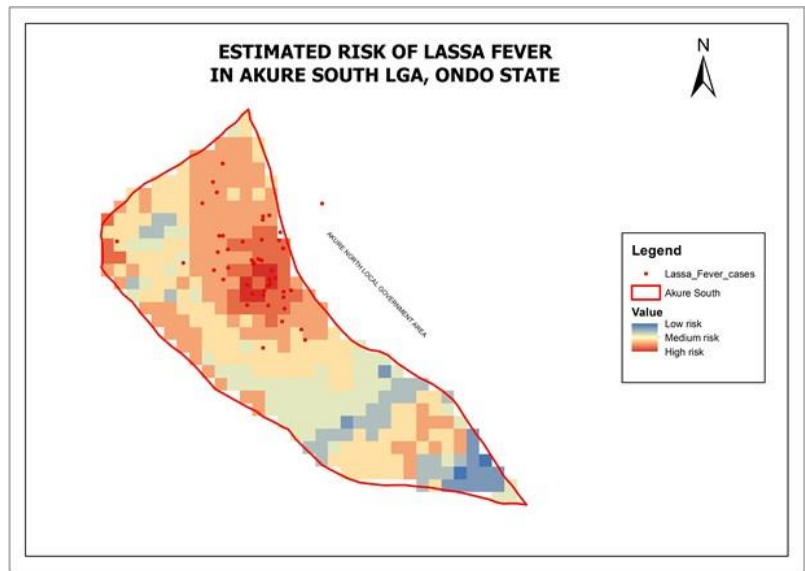

Figure 5. Showing estimation of risk: high risk areas (red) to low-risk areas (blue)

This map shows the location of where Lassa fever has occurred and predictive measures that show where is prone to Lassa fever occurrence to occur. Also, it showed the rate at which the disease is fast spreading to other territories. The places with red wine likely to experience a higher risk of Lassa fever cases, followed by peach to sky blue with low-risk Lassa fever.

\subsection{Closest Facility Analysis}

The closest facility analysis determined the accessibility of incidence of Lassa fever cases to health facilities. 60 incidences were imported, and 59 of them had the route to link them to 121 facilities on a $500 \mathrm{~m}$ tolerance. This shows that there are more than enough facilities within the study area, and the facilities are $90 \%$ accessible. The length of the routes generated to each of these facilities was calculated. The route generated is categorized based on how much the travel distance is taken for a person at the location of incidence to reach the closest facilities. The result is presented in Table 3

\begin{tabular}{|c|c|}
\hline Length (meters) & Number \\
\hline $1-400$ & 34 \\
\hline $401-800$ & 15 \\
\hline $801-1200$ & 6 \\
\hline 1200 and above & 5 \\
\hline Total & $\mathbf{6 0}$ \\
\hline
\end{tabular}

Table 3. Route Category

The pie chart in figure 6 showed that $57 \%$ of the roads are between $1 \mathrm{~m}$ and $400 \mathrm{~m}$. This implies that more than the average of the route to health facilities are trekkable. The figure also indicates that there is a well-distributed number of facilities over the area.

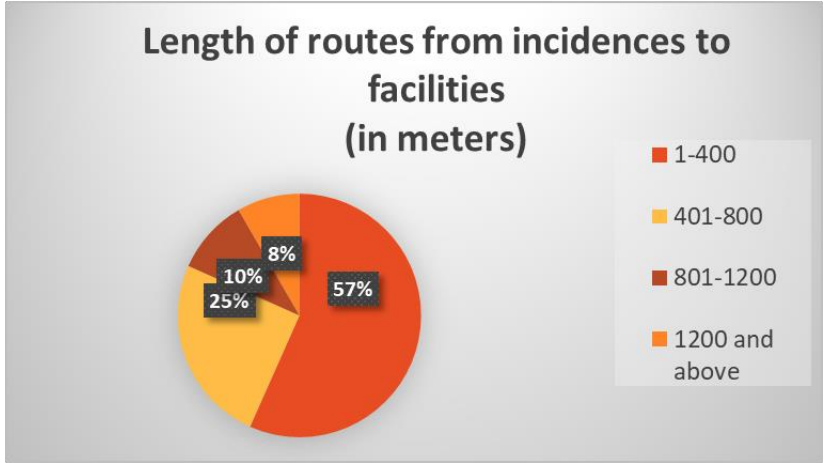

Figure 6. Pie chart of the length of routes from incidences to facilities

\subsection{Nearest Neighborhood analysis (NNA)}

The average nearest neighbor diagram shows that Lassa fever cases exhibit a cluster pattern since the average nearest neighbor ratio is less than 1. Figure 7 shows clustered spatial distribution of Lassa fever cases over the study area.

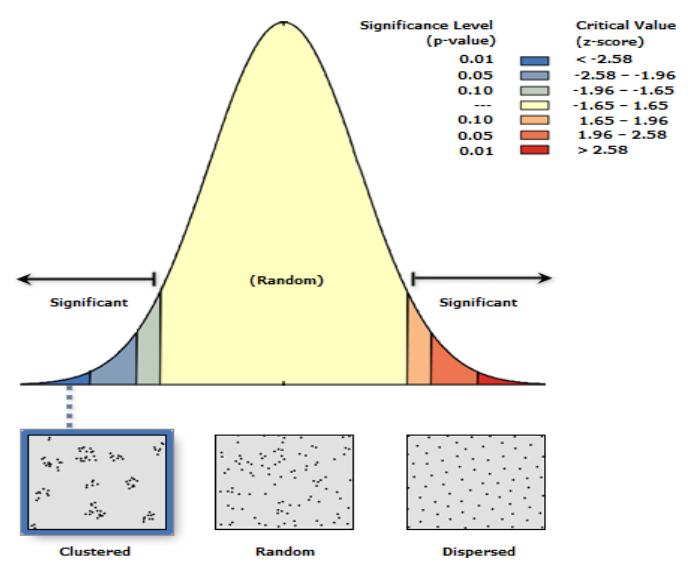

Figure 7: Average Nearest Neighbor for Lassa Fever

\subsection{Relationship between Lassa fever Cases and Environmental Variables}

In showing the relationship between Lassa fever cases and rainfall data, we considered to plot the number of cases in the percentage against the average rainfall percentage from 2016 to 2018 from January to December. Furthermore, it shows that there is an inverse proportion between rainfall and theoccurrence of Lassa cases. In January, which is known to be the dry season. It has been revealed that the cases are more pronounced in the dry season than in the wet season. Furthermore, when the rainy season comes up around September from the chart above, it is revealed that the cases are reduced drastically. Also, from various literature such as Monath, T. P. (1975), it was gathered that the host of Lassa viruscontacts the virus in the humid season, and they infect human beings during the dry season when they enter human houses in the food search. As shown in figure 8, the cases are in the blue chart and rainfall in orange. 


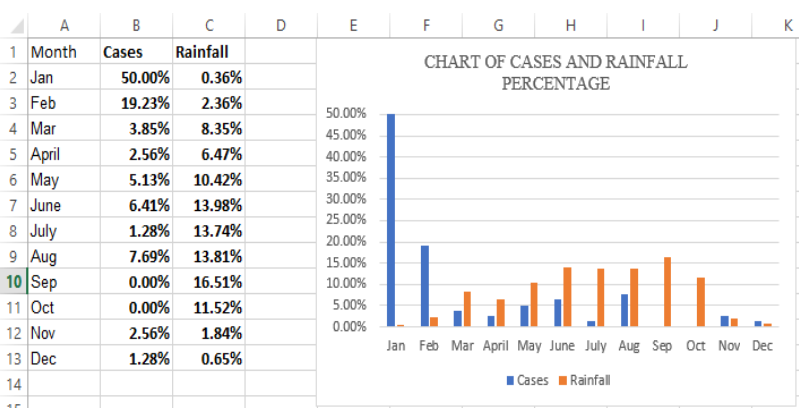

Figure 8. Chart showing the data and bar chart of cases and rainfall percentage

Figure 8 above shows the distribution of the number of cases and rainfall; as explained earlier above, it has been shown that there is an inversely proportional relationship between the two variables. Such that if rainfall is increasing, Lassa fever cases are decreasing. From the below figure 9, the correlation value is -0.494 choose that the two variables are not correlated.

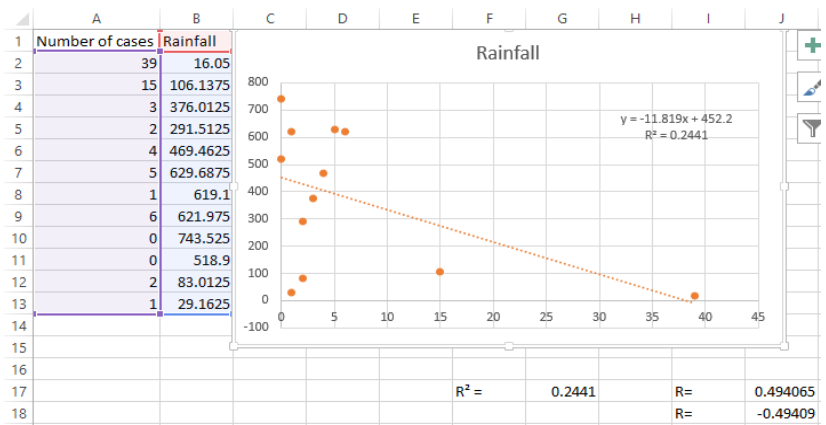

Figure 9. Graph showing the correlation between rainfall and Lassa fever cases

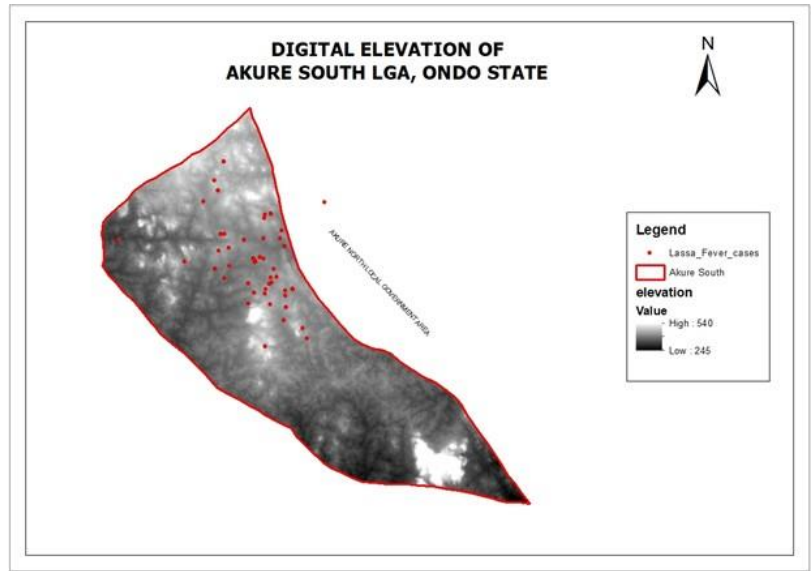

Figure 10. Map showing digital elevation model of Akure south

Figure 10 above shows the study area's elevation, and it depicts the high elevation to low elevation. It shows that areas with high elevation are the area with high concentrations of Lassa fever cases. Besides, low elevation is with less or no cases at all. The areas with high elevation are areas with light colour, and areas with low elevation are the areas with dark colour, and it ranges from 540 to 245

\subsection{Analyzing Lassa fever and its relationship with vegetation}

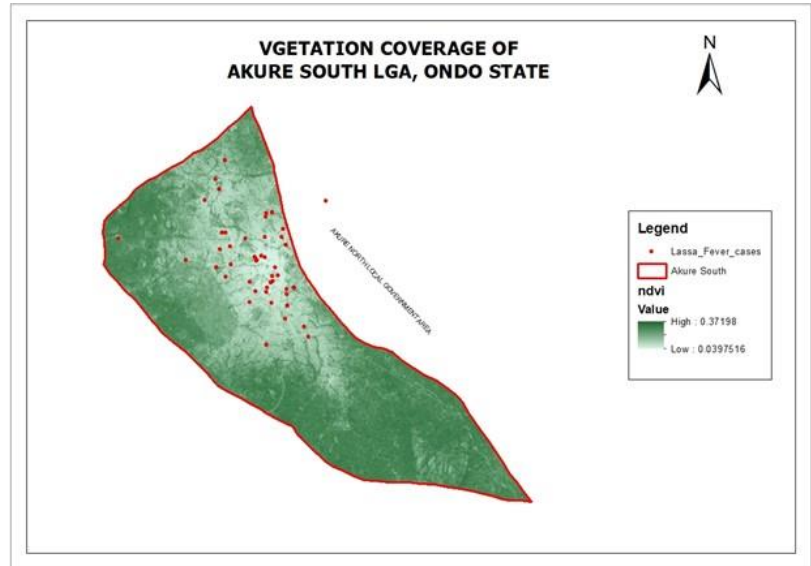

Figure 11. Map of vegetation coverage of Study Area

Figure 11 shows the vegetation coverage of the study area, and it depicts places with high vegetation coverage to the low area vegetation coverage. This shows that the areas with high vegetation are the areas with low concentrations of Lassa fever cases and areas with low vegetation coverage with high Lassa fever concentration. The areas with tower vegetation coverage are areas with light colour. High vegetation areas are areas with a dark green range from Normalized Difference Vegetation Index (NDVI) value of 0.37198 to 0.0397516 . Negative values of NDVI (values approaching -1) relate to water. Values close tozero ( -0.1 to 0.1$)$ mostly correspond to barren areas of rock, sand. Lastly, low positive values represent shrub and grassland (approximately 0.2 to 0.4 ), in which the above map value for NDVI falls within this range, while high values indicate temperate and tropical rainforest. The NDVI is a simple graphical indicator that can be used to analyze and assess whether the target being observed contains live green vegetationor not. It quantifies vegetation by measuring the difference between near-infrared (which vegetation strongly reflects).

\section{CONCLUSION}

This study figured out that Lassa fever occurrence is clustered and more prevalent during the dry season compared to the rainy season. The study also discovered that almost all Akure South Local Government's health facilities are accessible for treating Lassa fever. However, very few of them can treat Lassa fever patients. The risk map produced provides a pictorial view of locations prone to Lassa fever occurrence in the nearest future. This will inform a wider community and public health officers about places with the potential risk of Lassa fever.

\section{ACKNOWLEDGEMENTS}

The corresponding authors wish to acknowledge the support of Mr Gboyega Adekunle Famokun, Coordinator for disease surveillance at the Ondo state Primary Health CareDevelopment Board (OSPHCD), for providing access to the LF data used for this work. 


\section{REFERENCES}

Abasola O. Olugasa, J. B. D. (2015). Mapping of Lassa fever cases in post - conflict Liberia , 2008-2012: A descriptive and categorical analysis of age, gender and seasonal pattern. 14(2).

Afolabi, O. J., Akinneye, J. O., \& Igiekhume, A. M. A. (2019). Identification, abundance, and diversity of mosquitoes in Akure South Local Government Area, Ondo State, Nigeria. 4.

Elisabeth Fichet and Calvet, D. J. (2009). Risk Maps of Lassa Fever in West Africa. (U. o. Robert Tesh, Ed.) Evolutionary Ecology Group,Spatial Ecology and Epidemiology Group(3(3): e388.). doi:0.1371/journal.pntd.0000388

Eze, K. C., Salami, T. A. T., Eze, I. C., Pogoson, A. E., Omordia, N., \& Ugochukwu, M. O. (2010). High Lassa Fever Activity in Northern Part of Edo State, Nigeria: Re- Analysis of Confirmatory Test Results, 17(3), 52-56.2.

Fisher-Hoch SP, T. O.-O. (1995). Review of cases of nosocomial Lassa fever in Nigeria: the high price of poor medical practice. Volume 3(Issue No. 11), Pp857-859.

Geograhic Information Technology Training Alliance "Suitablity Analysis: Weighted Overlay: What is Weighted Overlay?." 2013 [Internet] Available from: http://www.gitta .info/Suitability/en/html/WeightOverla_learningObject1.html

Gibb, R., Moses, L. M., Redding, D. W., \& Jones, K. E. (2017). Understanding the Cryptic Nature of Lassa Fever in West Africa. in Pathogens and Global Health (Vol. 7724). https://doi.org/10.1080/20477724.2017.1369643

Gupta, R.; Jay, D.; Jain, R. (2003). Geographic Information Systems for the Study and Control of Infectious Diseases. Map India Conference, January. Paper No: 38

<http://www.gisdevelopment.net/application/health/overview/pd f/113.pdf> (accessed March, 2006), 1-7.

Hanafi-Bojd, A. A., Vatandoost, H., Oshaghi, M. A., Charrahy, Z., Haghdoost, A. A., Zamani, G., ... Raeisi, A. (2012). Spatial analysis and mapping of malaria risk in an endemic area, south of Iran: A GIS based decision making for planning of control. Acta Tropica, 122(1), 132-137. https://doi.org/10.1016/j.actatropica.2012.01.003

Hay, S.I.; Randloph, S.E.; Rogers, D.J. (2002) Remote Sensing and Geographic Information Systems. In Epidemiology: Advances in Parasitology 47; Baker, J.R.; Muller, R.; Rollinson, D.; Series Eds.; ISBN 0-12-031747-8. Oxford, UK, 357 pp.

Ibidolapo Taiwo Ijarotimi1and O. S.A.M. (2018). Knowledge of Lassa fever and use of infection prevention and control facilities among health care workers during Lassa fever outbreak in Ondo State, Nigeria. . Article in Pan African Medical Journal. doi: 10.11604/pamj.2018.30.56.13125

Jerrett, M.; Burnett, R.T.; Goldberg, M.S.; Sears, M.; Krewski, D.; Catalan, R.; Kanaroglou, P.; Giovis, C.; Finkelstein, N. (2003). Spatial analysis for environmental health research:
Concepts, methods, and examples. J. Toxicol. Environ. Health Pt. A,1783-1810.

Kaushal, A.; Johnson, C.P. (2003). Disease Surveillance Using GIS and Remote Sensing. Indo French Workshop on TeleEpidemiology of Dengue, Pune, Egypt.

<www.cdac.in/html/pdf/geomat/Paper-Kaushal-Johnson.pdf> (accessed March, 2006), 1-2.

Koch T. (2012). Disease Maps: Epidemics on the Ground. Chicago, IL: University of Chicago Press, 51-58.

Kunfoniyi O., (1998), Principles of Geographic Information system (series in surveying and geoinformatics, Panaf Press, Lagos).

Monath, T. P. (1975). Lassa fever: review of epidemiology and epizootiology. Bulletin of the World Health Organization, 52(4$56), 577-592$.

Monath TP, Newhouse VF, Kemp GE, Setzer HW, Cacciapuoti A (1974) Lassa Virus Isolation from Mastomys Natalensis Rodents During an Epidemic in Sierra Leone. Science 185,263265.

Omosehinmi, D. E., \& Arogunjo, A. M. (2016). Geostatistical investigation and ambient radiation mapping of Akure northand south local government areas of Ondo state, Nigeria. 1(12),122136.

Prashanthi Devi, M., Manickiam, B., Balasubramanian, S. (2003). Use of Remote Sensing and GIS for Monitoring the Environmental Factors Associated with Vector-Borne Disease (Malaria). Proceedings of the Third International Conference on Environment and Health, Chennai, India. Department of Geography, University of Madras andFaculty of Environmental Studies, York University, pp. 127-137.

Richmond J.K, Baglole D.J. (2003). Lassa Fever:Epidemiology, Clinical Features and Social Consequences. British Medical Journal, 327, $1271-1275$.

Saka, J. M., Bintu Gubio, A., Kerecvel, Y. S., Saka, A. O., \& Oyemakinde, A. (2017). Lassa Fever Epidemic in Nigeria Outbreak Investigation, Risk Factors and Empirical Analysis from 2012 To 2016. Journal of Community \& Public Health Nursing, 03(02).

World Health Organization (2017). List of Blueprint priority diseases (revised January 2017) [Internet]. [cited 2017 Aug 10]. Available from: http://www.who.int/blueprint /priority diseases/en/ 